\title{
Lifestyle and Health Habits of a Canadian University Community
}

\author{
Alexandre Busque ${ }^{1, *}$, Pierre-Luc Yao ${ }^{1}$, Paule Miquelon ${ }^{2}$, Émilie Lachance $^{1}$, Marie-Claude Rivard ${ }^{1}$ \\ ${ }^{1}$ Department of Human Kinetics, University of Quebec at Trois-Rivieres, Trois-Rivieres, Canada \\ ${ }^{2}$ Department of Psychology, University of Quebec at Trois-Rivieres, Trois-Rivieres, Canada \\ *Corresponding author: alexandre.busque@uqtr.ca
}

\begin{abstract}
In 2014, World Health Organization reported that more than 1.9 billion people were obese (World Health Organization, 2014). This epidemic is thought to cost \$2 trillion globally every year (Dobbs et al., 2014). With the increase of the prevalence of obesity, there is a continuous search for effective obesity-prevention and health promotion strategies. In a Canadian university, Perusse-Lachance and colleagues (2010) showed that 22.9\% of students and $37.3 \%$ of staff members were either overweight or obese. The purpose of this study was to examine the prevalence of obesity, healthy lifestyle habits, and healthy environments among students and employees of a Canadian university. Respondents were students and employees during the 2016 fall semester (October). A web based-survey assessing lifestyle habits, such as physical activity and nutrition, was sent by email to all students ( $\mathrm{n}=$ $15,000)$ and employees $(n=1,500)$. In total, 1,989 students $(12.1 \%)$ and 484 employees $(33.6 \%)$ completed the questionnaire. All data were analyzed using SPSS. Results showed that $32.7 \%$ of students and $44.5 \%$ of employees were overweight. Results also revealed that $55.2 \%$ of students and $44.9 \%$ of employees were considered physically inactive. Regarding vegetables and fruit, $81.2 \%$ of students and $79.4 \%$ of employees did not meet the Canadian recommendations. The herein results suggest that overweight and obesity can be important concerns in a welleducated sample and they can be associated with various health-related behaviors.
\end{abstract}

Keywords: lifestyle habits, students, employees, physical activity, food habits

Cite This Article: Alexandre Busque, Pierre-Luc Yao, Paule Miquelon, Émilie Lachance, and Marie-Claude Rivard, "Lifestyle and Health Habits of a Canadian University Community." Journal of Physical Activity Research, vol. 2, no. 2 (2017): 107-111. doi: 10.12691/jpar-2-2-7.

\section{Introduction}

In 2003, the World Health Organization (WHO) described obesity as an epidemic [3] and in 2014, it reported that more than 1.9 billion people were obese [1]. This epidemic is thought to cost $\$ 2$ trillion globally every year [2]. Obesity is associated with increased risks of cardiovascular disease, type 2 diabetes, arthritis, and some types of cancers [4]. However, weight gain is common during young adulthood [5]. In 2014, 39\% of adults were overweight compared to $28.9 \%$ in 1980 [1]. Among Canadian adults, rates of overweight went from $27.8 \%$ in 1985 to $33.6 \%$ in 2012, while obesity rates tripled in the same period, from $6.1 \%$ to $18.3 \%$ [6]. Therefore, evidence-based multi-level public health interventions could improve obesity-related behaviors in adults [7]. There is a growing agreement among experts that the environment rather than biology is driving this epidemic $[8,9,10]$. Biology clearly contributes to individual differences in weight and height, but the rapid weight gain that has occurred over the past three decades is a result of the changing environment [8]. In this regard, since 1980, it has been reported that students gain a significant amount of weight during their first year of university. The phenomenon has been called the 'Freshman 15,' in reference to the perception that students gain 15 lbs (6.8 $\mathrm{kg}$ ) during their first year of university [11]. However, studies have shown that the weight increase actually ranges between $0.7 \mathrm{~kg}$ and $3.1 \mathrm{~kg}$ [12].

The literature shows that among university students, weight gain is associated with poor eating habits, stress, and lower physical activity following the transition from a structured high school environment to university $[12,13,14]$. Because students do experience important weight changes, universities need to focus on increasing health promotion to help them maintain/adopt healthy behaviors [13]. Therefore, the purpose of this study was to examine the prevalence of obesity, healthy lifestyle habits, and healthy environments among students and employees of a Canadian university to develop healthy lifestyle promotion strategies.

\section{Materials and Methods}

\subsection{Design, Participants and Data Analysis}

This descriptive study used a cross-sectional design, and data were collected during the fall semester of the academic year. An e-mail including a hyperlink to an online questionnaire was sent at the beginning of October 2016 to every student $(\mathrm{n}=15,000)$ and employee $(\mathrm{n}=$ 
1,500), and a recall was sent at the end of October. In total, 2,473 participants completed the questionnaire, representing $14.9 \%$ of the university community. The final sample was composed of 1,989 students $(\mathrm{F}=76.6 \%$; $\mathrm{M}=23.4 \%)$ and 484 employees ( $\mathrm{F}=65.9 \% ; \mathrm{M}=34.1 \%)$. Data were analyzed using SPSS (version 24) and descriptive statistics (means, standard deviations, percentages, and frequencies), and the t-test $(\mathrm{t})$ and Chi-squared test $(\chi 2)$ were utilized to verify statistical differences and associations between gender (female vs. male), between status (students vs. employees), and between other variables, such as body mass index (BMI) and physical activity. The ethics board of the home university approved this study, and all participants signed an informed consent form.

\subsection{Measures}

The questionnaire (153 questions) used to collect data was comprised of six sections: 1) general information and general health, 2) physical activity habits, 3) nutritional habits, 4) other lifestyle habits, 5) physical activity environments, and 6) food environments. The official guidelines recommended by the Canadian Government were used. Therefore, the physical activity standard was based on the Canadian Society of Exercise Physiology [15] and the standard for nutritional habits was based on the Canadian Food Guide [16]. The variables assessed by the questionnaire are described below.

Body mass index. BMI was used to classify the participants as underweight, normal weight, overweight, or obese. BMI is a simple index using a weight-to-height ratio, and it is defined as weight in kilograms divided by the square of the height in meters $(\mathrm{kg} / \mathrm{m} 2)$ [1].

Physical activity. The 2011 Canadian Society of Exercise Physiology (CSEP) guidelines suggest 150 minutes of moderate to vigorous physical activity per week for adults in bouts of 10 minutes or more [15] and these were used for all questions assessing self-reported physical activity.

Nutritional habits. The Canadian Food Guide was used as a standard of healthy eating for adults. This Guide presents four food groups (vegetables and fruit [V\&F], grain products, dairy and alternatives, and meat and alternatives), and each group has a standard portion [16]. We used this standard portion as a reference for V\&F when participants had to report their intake for each day.

Environments. The questions assessing environments were based on Quebec's Minister of Health and Social Services' model, entitled, "Pour une vision commune des environnements favorables à la saine alimentation, à un mode de vie physiquement actif et à la prévention des problèmes reliés aux poids" [17]. This model presents four different types of environments: physical, socio-cultural, political, and economic. However, only the perceived physical and socio-cultural environments and their influence on behaviors associated with physical activity and nutrition were measured in the present study.

\section{Results}

The findings of this study are presented according to the four outcomes described above: BMI, physical activity, nutritional habits, and environments. The sample's characteristics are presented in both Table 1 and Table 2. Table 1 describes participants' characteristics according to their gender, while Table 2 describes participants' characteristics according to their status. As shown, the mean age for students was $25(S D=7.3)$ years, $46(S D=$ 9.9) years for employees and $29(S D=7.6)$ years for the overall sample. On average, females were $29(S D=10.8)$ years old and males were 31 (12.6) years old.

Table 1. Characteristics of sample by status

\begin{tabular}{|c|c|c|}
\hline \multirow{2}{*}{ Characteristics } & \multicolumn{2}{|c|}{ University status } \\
\cline { 2 - 3 } & Students & Employees \\
\hline $\mathrm{N}$ & $1989(80.4)$ & $484(19.6)$ \\
\hline Women (\%) & $1517(76.6)$ & $319(65.9)$ \\
\hline Men (\%) & $463(23.4)$ & $165(34.1)$ \\
\hline Age, mean, yrs & $25.63(7.32)$ & $46.04(9.9)$ \\
\hline BMI, mean, kg/m ${ }^{2}$ & $24.24(4.8)$ & $25.23(4.4)$ \\
\hline
\end{tabular}

Table 2. Characteristics of sample by gender

\begin{tabular}{|c|c|c|}
\hline \multirow{2}{*}{ Characteristics } & \multicolumn{2}{|c|}{ Gender } \\
\cline { 2 - 3 } & Women & Men \\
\hline $\mathrm{N}(\%)$ & $1865(74.2)$ & $637(25.3)$ \\
\hline Age, mean, yrs & $28.98(10.8)$ & $31.49(12.6)$ \\
\hline BMI, mean, kg/m ${ }^{2}$ & $24.16(4.9)$ & $25.18(4.1)$ \\
\hline
\end{tabular}

Body mass index

As presented by Table 3, 32.7\% students and 44.5\% employees (35\% of the overall sample) in total were considered overweight (BMI $\geq 25$ ) or obese (BMI $\geq 30$ ). Students had a lower BMI than employees (24.2 [SD = 4.8] $\mathrm{kg} / \mathrm{m}^{2}$ vs. $25.2[S D=4.4] \mathrm{kg} / \mathrm{m}^{2}$ ), and this difference was statistically significant $\left(t_{2439}=-4.65 \mathrm{p}<0.001\right)$. Regarding gender, $31.1 \%$ of females and $46.1 \%$ of males were considered overweight. Moreover, males had a significantly higher BMI than females (25.2 [SD = 4.9] $\mathrm{kg} / \mathrm{m}^{2}$ vs. $\left.24.2[S D=4.1] \mathrm{kg} / \mathrm{m}^{2}\right)\left(t_{2450}=-4.05 \mathrm{p}<0.001\right)$. Table 3 presents the prevalence of overweight and obesity in the sample according to participants' status and gender.

Table 3. Prevalence of overweight and obesity

\begin{tabular}{|c|c|c|}
\hline \multirow{2}{*}{ BMI categories } & \multicolumn{2}{|c|}{ University status } \\
\cline { 2 - 3 } & Students & Employees \\
\hline Underweight, (\%) $<18.5 \mathrm{~kg} / \mathrm{m}^{2}$ & $86(4.5)$ & $5(1.1)$ \\
\hline Normal, (\%) 18.5 to $25 \mathrm{~kg} / \mathrm{m}^{2}$ & $1209(62.8)$ & $256(54.6)$ \\
\hline Overweight, (\%) 25 to $30 \mathrm{~kg} / \mathrm{m}^{2}$ & $402(20.9)$ & $148(31.6)$ \\
\hline Obesity class 1, (\%) 30 to $35 \mathrm{~kg} / \mathrm{m}^{2}$ & $151(7.8)$ & $42(9)$ \\
\hline Obesity class $2,(\%) 35$ to $40 \mathrm{~kg} / \mathrm{m}^{2}$ & $53(2.8)$ & $14(3)$ \\
\hline
\end{tabular}

Physical activity

In terms of physical activity, $54.1 \%$ of the sample was not sufficiently active to meet the recommended guidelines of 150 minutes of moderate to vigorous physical activity per week. The Figure 1 describes some Canadian health recommendations. According to the CSEP guidelines, $55.2 \%$ of students and $49.9 \%$ of employees were considered physically inactive, and in general, students tended to be more active than employees $(\chi 2=25.11, p<0.001)$. Furthermore, female (58.8\%) reported being more inactive than male $(49.9 \%)(\chi 2=48.81$, $\mathrm{p}<0.001)$. In addition, $33.6 \%$ of students and $58.6 \%$ of employees (40.2\% of women and $34.3 \%$ of men) reported using any active transportation. 


\section{Nutritional habits}

Regarding food habits, only $19.1 \%$ of the sample met the minimal recommended intake of V\&F. In total, $81.2 \%$ of students and $79.4 \%$ of employees did not meet the recommended portions per day of V\&F of seven for women and eight for men. The mean daily V\&F consumption for students was 4.54 (2.61) portions, while it was 5.05 (2.7) portions for employees. V\&F consumption was significantly higher among employees than among students (t2439 $=-3.46 \mathrm{p}<0.001)$. In addition, $72.9 \%$ of women and $86.6 \%$ of men did not meet the recommendation for $\mathrm{V} \& \mathrm{~F}$ intake. The mean number of portions was $4.73(\mathrm{SD}=2.55)$ for women and $4.51(\mathrm{SD}=$ 2.92) for men. There was no significant difference in the number V\&F portions between women and men $(\mathrm{t} 2310=$ 1.76, $\mathrm{p}<.08$ ). Furthermore, $78.9 \%$ of the community reported eating breakfast every day. More specifically, $76.1 \%$ of students and $89.9 \%$ of employees indicated they were having breakfast every morning.

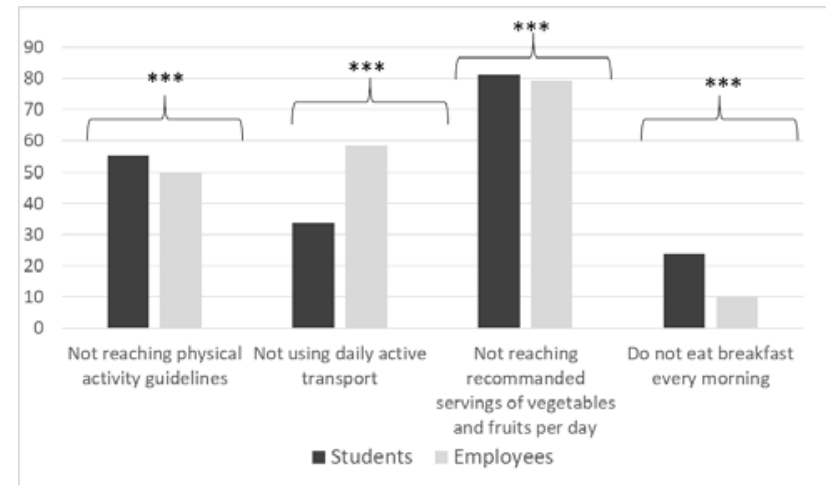

Figure 1. Percentage of students and staff members who do not reach the Canadian health recommendations $(* * *=p<0.001)$

\section{Environments}

As for perceived environments, only $8 \%$ of students and employees reported that the campus environment was not meeting their physical activity values and/or needs. As for food environments, $32 \%$ of students and $26 \%$ of employees reported that the campus environment was not meeting their values and/or religious needs.

\section{Discussion}

The purpose of this study was to examine university community lifestyle to develop healthy lifestyle promotion strategies specific to this community.

Body mass index

Despite the sample's high level of education, the results revealed that $35 \%$ of the population $(32.7 \%$ of students and $44.5 \%$ employees) was overweight or obese. This result seems to agree with prior studies, such as PérusseLachance, Tremblay, and Drapeau [18], who revealed in a Canadian university that despite high education levels, $22.9 \%$ of students and $37.3 \%$ of staff members were overweight [18]. Men tend to be more overweight than women (46.1\% vs. 31.1\%). These results are lower than the Canadian Community Health Survey's findings related to BMI, which revealed that $54 \%$ of the Canadian population was overweight and that men tend to be more overweight then women (61.8\% vs. $46.2 \%)$ [19].
In the United States, many studies have tackled this question. Our results also seem to be comparable to most findings in the US, as the American College and Health Association reported that $34.1 \%$ of college students are currently overweight or obese [20]. Similarly, Nicoteri and Miskovsky [21] found that $32 \%$ of students were overweight or obese at the end of the senior or graduate year. Although, this does not seem to be a consensus in the literature, because some studies, such as Gropper et al. [14] and Racette, Deusinger, Strube, Highstein, and Deusinger [22] found that the percentage of overweight and obese students was lower, at $24 \%$ at the end of the junior year and $18 \%$ at the end of the sophomore year.

Physical activity

The herein results demonstrate that healthy habits and body weight vary according to gender and university status. Male students generally exhibit less desirable food habits, although they are more physically active. These results are in line with prior research, which demonstrated that men tend to be more active than are women, both worldwide [23] and in Canada [24]. In addition, more students than employees reported not meeting the CSEP recommendation of 150 minutes of moderate to vigorous physical activity per week (49.9\% vs. 55.2\%). Our sample was considered more physically inactive (54\%) than that surveyed by the Canadian Community, which found that $46.3 \%$ of people were considered physically inactive [19]. However, our sample was considered less physically inactive (54\% vs. 66\%) than that examined by PérusseLachance et al. [18].

Nutritional habits

Regarding nutritional habits and gender differences, the herein results are also in line with those found in a Canadian university community context [25] and in the literature in general [26], Indeed, it has been found that male students generally exhibit less desirable food habits, such as lack of V\&F consumption and skipping breakfast. Breakfast consumption has been associated with a lower likelihood of being overweight [27]. Our results showed that men had a greater tendency to skip breakfast $(20.7 \%$ vs. $19.8 \%$ ). Students also had a tendency to skip breakfast more and to snack less. To our knowledge, only one research study, conducted by Pérusse-Lachance et al. [18] has studied lifestyle habits among a Canadian university sample. In this particular study, Pérusse-Lachance and colleagues found that students also seemed to skip breakfast more than did employees [18]. These findings seem to follow previous studies that showed $30 \%$ of the adult population skips breakfast. Thus, when it comes to nutritional habits, most of our findings are similar to those obtained by Pérusse-Lachance et al., (2010). More precisely, students had less desirable eating patterns, in general, than did employees. These results seem to support the "Freshman 15" phenomenon. Knowing most students tend to gain $0.7-3.1 \mathrm{~kg}$ in the first year of university [12], it would make sense to assume that their health behaviors are not as beneficial as those of the staff member given that recent studies [28] have found an association between healthy habits and weight gain among adults.

Environments

There is a growing body of research on the importance of environments in adopting healthy behaviors [9,10]. In fact, the environment can both facilitate and hinder 
physical activity [29] and healthful eating [30]. For example, the increase in the supply of cheap, palatable, energy-dense foods and improved distribution systems have made food much more accessible and convenient, therefore making it easier to be in a calorie surplus [10].

In our study, $32 \%$ of students and $26 \%$ of employees reported that the campus environment was not meeting their food or nutritional values and needs. Because it has been demonstrated that socio-cultural environments can play an important role in eating habits and weight gain, [31]. Therefore, environments could potentially hinder healthy habits in this community. In that regard, only $33.6 \%$ of students compared to $58.6 \%$ of employees reported using active transportation. This could potentially underline obstacles that may be introduced by the build environment. As previous studies have shown an association between living in the most walkable neighborhoods [32] and having a lower BMI in adults of all ages, it see could be interesting to study what may pose barriers to active transportation and to study the effect of those barriers on healthy habits.

Limitations

The herein research has some limitations and therefore, the results should be interpreted with caution. First, this study is based on self-reported data, which are subject to social bias. As pointed out in the literature, a comparison of self-reported and objective measures often indicates that respondents under-report their weight and over-report their height, leading to an underestimation of BMI [33]. Second, this study used a cross-sectional design, and therefore, it cannot provide evidence of a causal link between lifestyle habits and obesity. In counterpart, the high participation rate (15\%) compared to similar studies, such as Pérusse-Lachance et al. [18], can be considered a strength, because the results can be generalized more easily to the whole university community. Of note is that although an email and one reminder were sent to every student and employee, more participants from health departments, such as physical activity, psychology, chiropractic, and nursing, answered the questionnaire. For example, regarding level of physical activity, our sample was more active than that surveyed Racette et al. [22], Keating, Guan, Pinero, and Bridges [34] and Pérusse-Lachance et al. [18]. This could be explained by the fact that we had a high proportion of students and employees (30.6\%) from health departments, which could lead to a slight bias in the results of our study, as health departments represent only $17.2 \%$ of the total community in our population. As such, participants from these departments are overrepresented in the sample and as they probably have more healthy habits than do others, the present findings could be slightly biased.

\section{Conclusion}

In conclusion, we believe that this study can serve as a model for a health promotion program in other organizations and health care institutions. In this context, our study mainly demonstrates that lifestyle habits of this university community could be greatly improved, therefore supporting the need to develop and evaluate health promotion and obesity prevention and interventions in university communities. Therefore an approach targeting the physical activity and food habits with a view to promote health could greatly benefit this university community in this regard. Environments should also be considered and studied to assess the type of intervention that would affect individuals' health behaviors. Further research should target specific health promotion interventions in these kinds of communities to prevent weight gain and promote healthy eating and active lifestyles. Longitudinal research could measure the effects of a health promotion program on lifestyle habits or on motivational factors regarding lifestyle habits. Further research could also measure more clinical variables on a smaller sample, such as VO2 max, body fat or blood test, etc., to adapt interventions more accurately to this community.

\section{Acknowledgements}

\section{Conflict of interest disclosure}

The authors have no conflicts of interest to report. The authors confirm that the research presented in this article met the ethical guidelines and received approval from the Human Research Ethics Committee (CER-15-219-07.11).

\section{Funding}

This work was supported by "Fonds Institutionnel de Recherche Clinique” from the home university.

\section{References}

[1] World Health Organization, "Obesity and overweight", 2016 (February 2017), 2014.

[2] Dobbs, R., Sawers, C., Thompson, F., Manyika, J., Woetzel, J., McKenna, S., \& Spatharou, A., Overcoming obesity: An initial economic analysis, McKinsey Global Institute, 2014.

[3] World Health Organization, "Obesity: preventing and managing the global epidemic", 2016(5 février), 2003.

[4] Kopelman, P. G., "Obesity as a medical problem", Nature, 404(6778), 635-643, 2000.

[5] Norman, J. E., Bild, D., Lewis, C. E., Liu, K., West, D. S., \& Study, C., "The impact of weight change on cardiovascular disease risk factors in young black and white adults: the CARDIA study", International Journal of Obesity Related Metabolic Disorders, 27(3), 369-376,2003.

[6] Twells, L. K., Gregory, D. M., Reddigan, J., \& Midodzi, W. K. "Current and predicted prevalence of obesity in Canada: a trend analysis", Canadian Medical Association Journal, 2(1), E18-26, 2014.

[7] Compernolle, S., De Cocker, K., Lakerveld, J., Mackenbach, J. D., Nijpels, G., Oppert, J. M., Rutter, H., Teixeira, P. J., Cardon, G., \& De Bourdeaudhuij, I., "A RE-AIM evaluation of evidence-based multi-level interventions to improve obesity-related behaviours in adults: a systematic review (the SPOTLIGHT project)", International Journal Behavioral Nutrition Physical Activity, 11, 147, 2014.

[8] Hill, J. O., Wyatt, H. R., Reed, G. W., \& Peters, J. C., "Obesity and the environment: where do we go from here?", Science, 299(5608), 853-855,2003. doi:10.1126/science.1079857

[9] Booth, K. M., Pinkston, M. M., \& Poston, W. S., "Obesity and the built environment", Journal of American Dietetic Association, 105(5 Suppl 1), S110-117, 2005.

[10] Swinburn, B. A., Sacks, G., Hall, K. D., McPherson, K., Finegood, D. T., Moodie, M. L., \& Gortmaker, S. L., "The global obesity pandemic: shaped by global drivers and local environments", The Lancet, 378(9793), 804-814, 2011. 
[11] Brown, C., "The information trail of the 'Freshman 15'--a systematic review of a health myth within the research and popular literature", Health Information and Libraries Journal Health, 25(1), 1-12, 2008.

[12] Crombie, A. P., Ilich, J. Z., Dutton, G. R., Panton, L. B., \& Abood, D. A., "The freshman weight gain phenomenon revisited", Nutrition Reviews, 67(2), 83-94,2009.

[13] Vadeboncoeur, C., Townsend, N., \& Foster, C., "A meta-analysis of weight gain in first year university students: is freshman 15 a myth?", BMC Obesity, 2, 22, 2015.

[14] Gropper, S. S., Simmons, K. P., Connell, L. J., \& Ulrich, P. V., "Weight and Body Composition Changes during the First Three Years of College", Journal of Obesity, 2012, 634048, 2012.

[15] Canadian Society of Exercise Physiology, Canadian physical activity guidelines, 2011.

[16] Minister of Health Canada, "Eating well with Canada's Food Guide : Food Guide Basics", 2017(March ), 2011.

[17] Minister of Health and Social Services, Pour une vision commune des environnements favorables à la saine alimentation, à un mode de vie physiquement actif et à la prévention des problèmes reliés au poids, Gouvernement du Québec,Québec, 2012.

[18] Pérusse-Lachance, É., Tremblay, A., \& Drapeau, V., "Lifestyle factors and other health measures in a Canadian university community", Applied Physiology, Nutrition, and Metabolism, 35(4), 498-506, 2010.

[19] Statistics Canada, "Canadian Community Health Survey - Annual Component (CCHS)", 2017(February), 2014.

[20] ACHA-NCHA, "American College Health Association National College Health Assessment (ACHA-NCHA) Spring 2005 Reference Group Data Report (Abridged)", Journal Of American College Health, 55(1), 5-16, 2006

[21] Nicoteri, J. A., \& Miskovsky, M. J., "Revisiting the freshman "15": assessing body mass index in the first college year and beyond", Journal of American Association of Nurse Practitioners, 26(4), $220-224,2014$.

[22] Racette, S. B., Deusinger, S. S., Strube, M. J., Highstein, G. R., \& Deusinger, R. H., "Weight changes, exercise, and dietary patterns during freshman and sophomore years of college", Journal of American College Health, 53(6), 245-251, 2005.

[23] Hallal, P. C., Andersen, L. B., Bull, F. C., Guthold, R., Haskell, W., Ekelund, U., \& Lancet Physical Activity Series Working, G. "Global physical activity levels: surveillance progress, pitfalls, and prospects", Lancet, 380(9838), 247-257, 2012.
[24] Colley, R. C., Garriguet, D., Janssen, I., Craig, C. L., Clarke, J., \& Tremblay, M. S., "Physical activity of Canadian adults: accelerometer results from the 2007 to 2009 Canadian Health Measures Survey", Health Reports, 22(1), 7-14, 2011.

[25] Dawson, K. A., Schneider, M. A., Fletcher, P. C., \& Bryden, P. J., "Examining gender differences in the health behaviors of Canadian university students", Journal of the Royal Society of Health, 127(1), 38-44, 2007.

[26] Peltzer, K., Pengpid, S., Yung, T. K., Aounallah-Skhiri, H., \& Rehman, R., "Comparison of health risk behavior, awareness, and health benefit beliefs of health science and non-health science students: An international study", Nursing \& Health Sciences, 18(2), 180-187, 2016.

[27] Song, W. O., Chun, O. K., Obayashi, S., Cho, S., \& Chung, C. E., "Is consumption of breakfast associated with body mass index in US adults?", Journal of the American Dietetic Association, 105(9), 1373-1382, 2005.

[28] Smith, K. J., Gall, S. L., McNaughton, S. A., Cleland, V. J., Otahal, P., Dwyer, T., \& Venn, A. J., "Lifestyle behaviours associated with 5-year weight gain in a prospective cohort of Australian adults aged 26-36 years at baseline", BMC Public Health, 17(1), 54, 2017.

[29] Christiansen, L. B., Cerin, E., Badland, H., Kerr, J., Davey, R., Troelsen, J., van Dyck, D., Mitas, J., Schofield, G., Sugiyama, T., Salvo, D., Sarmiento, O. L., Reis, R., Adams, M., Frank, L., \& Sallis, J. F., "International comparisons of the associations between objective measures of the built environment and transport-related walking and cycling: IPEN Adult Study", The Journal of Transport \& Health, 3(4), 467-478, 2016.

[30] Giskes, K., van Lenthe, F., Avendano-Pabon, M., \& Brug, J., "A systematic review of environmental factors and obesogenic dietary intakes among adults: are we getting closer to understanding obesogenic environments?", Obesity Reviews, 12(5), e95-e106, 2011.

[31] Ball, K., \& Crawford, D., The role of sociocultural factors in the obesity epidemic, INSPQ,Québec, 1-14, 2006.

[32] Loo, C. K., Greiver, M., Aliarzadeh, B., \& Lewis, D., "Association between neighbourhood walkability and metabolic risk factors influenced by physical activity: a cross-sectional study of adults in Toronto, Canada", BMJ Open, 7(4), e013889, 2017.

[33] Bowring, A. L., Peeters, A., Freak-Poli, R., Lim, M. S., Gouillou, M., \& Hellard, M., "Measuring the accuracy of self-reported height and weight in a community-based sample of young people", BMC Medical Research. 